\title{
O comércio eletrônico como ferramenta de comercialização para a agricultura familiar
}

\author{
Aldi Feiden \\ Universidade Estadual do Oeste do Paraná - Toledo - Paraná - Brasil \\ ORCID: https://orcid.org/0000-0002-6823-9291 \\ Manoel João Ramos \\ Faculdade da Indústria - Sistema FIEP/SENAl i - Toledo - Paraná - Brasil \\ ORCID: https://orcid.org/0000-0001-5052-9293 \\ Jéssica Schwanke \\ Universidade Estadual do Oeste do Paraná - Marechal Cândido Rondon - Paraná \\ - Brasil \\ ORCID: https://orcid.org/0000-0002-2809-5043
}

\section{Resumo}

O presente estudo visa caracterizar os produtores familiares rurais que comercializam na feira do produtor rural das cidades de Marechal Cândido Rondon, Toledo e Cascavel, pertencentes à região oeste do Paraná. De forma mais ampla, a investigação tem por objetivo analisar a utilização do comércio eletrônico como mercado alternativo e a intenção de expansão comercial. A metodologia caracteriza-se pelo estudo de campo, com abordagem qualitativa e quantitativa. Foi aplicado um questionário semiestruturado para um grupo de 69 agricultores. Os resultados obtidos apontam que os produtores rurais utilizam as redes sociais como forma comercial, porém, desconhecem o quanto essa forma de comercialização contribui para a renda mensal. $O$ estudo apresenta o mercado online como uma alternativa futura para a comercialização da produção, diante de que, os agricultores apontam que o número de pessoas que procuram os produtos pelas redes sociais e aplicativos de mensagens tem crescido. Entretanto, observam que não possuem quantidade suficiente em estoque para atender à crescente demanda, mas entendem que isso pode ser ajustado de acordo com a necessidade.

Palavras-chave: Agricultura Familiar. Comércio Eletrônico. Feiras. Internet.

\section{Abstract}

\section{E-commerce as a commercializing tool for familiar agriculture}

The present study aims characterize rural familiar producers that commercialize in the rural producer fair from the cities of Marechal Cândido Rondon, Toledo and Cascavel, which belong to the west region of Paraná. More broadly, the investigation has the objective of analyzing the use of electronic commerce as an alternative market and the purpose of commercial expansion. The methodology is characterized by a field study, made by a qualitative and quantitative approach. A semi-structured questionnaire was applied to a 
group of 69 farmers. The results show that rural producers use social networks in a commercial way, however, they are unaware of how much this form of marketing contributes to monthly income. The study presents the online market as a future alternative for marketing the production, given that farmers point out that the number of people looking for products through social networks and messaging applications has grown. However, they contrast that do not have enough stock to meet the growing demand, but this can be adjusted according to the need.

Keywords: Family Agriculture. E-commerce. Fairs. Internet.

\section{Comercio electrónico como herramienta de comercialización para la agricultura familiar Resumen}

El presente estudio tiene como objetivo caracterizar a los productores familiares rurales que comercializan en la feria de productores rurales de las ciudades de Marechal Cândido Rondon, Toledo y Cascavel, que pertenecen a la región oeste de Paraná. En términos más generales, la investigación tiene el objetivo de analizar el uso del comercio electrónico como un mercado alternativo y el propósito de la expansión comercial. La metodología se caracteriza por un estudio de campo, realizado mediante un enfoque cualitativo y cuantitativo, y se aplicó un cuestionario semiestructurado a un grupo de 69 agricultores. Los resultados muestran que los productores rurales usan las redes sociales de manera comercial, sin embargo, no son conscientes de cuánto contribuye esta forma de comercialización a los ingresos mensuales. El estudio presenta el mercado en línea como una alternativa futura para comercializar la producción, dado que los agricultores señalan que ha aumentado la cantidad de personas que buscan productos a través de las redes sociales y las aplicaciones de mensajería. Sin embargo, contrastan que no tienen suficientes existencias para satisfacer la creciente demanda, pero esto se puede ajustar según la necesidad.

Palabras clave: Agricultura familiar. Comercio electrónico. Ferias. Internet.

\section{Introdução}

Os estudos sobre a agricultura familiar no Brasil são frequentes e, geralmente, são impulsionados pela percepção da necessidade de atenção ao setor por meio de políticas de incentivo para o seu desenvolvimento. Os agricultores possuem diversos obstáculos em sua jornada e uma das mais citadas em vários estudos (SOUZA FILHO, et al., 2004; BUAINAIN, et al., 2003; ESTEVAM, et al., 2018; e HEBERLÊ, et al., 2017) está relacionada com o acesso aos mercados. A agricultura familiar tem ganhado relevância nos últimos anos diante do crescimento das feiras e lojas especializadas para comercialização dos produtos agroecológicos.

No Paraná 228.888 estabelecimentos rurais pertencem a agricultura familiar, (75\%), cerca de 74.000 entidades a menos que o Censo Agro 2006. As atividades econômicas no Estado concentram-se, principalmente, nas lavouras temporárias $(46,85 \%)$, seguido da pecuária e criação de outros animais (41,11\%), produção de lavouras permanentes $(5,24 \%)$ e horticultura e floricultura (3,55\%) (CENSO IBGE, 2017).

De acordo com a pesquisa, a região oeste do Paraná possui 32.152 estabelecimentos da agricultura familiar. Sendo que, as atividades econômicas da região concentram-se, principalmente, em lavoura temporária (53\%), pecuária e criação de outros animais (43\%) e horticultura e floricultura (1,7\%) (CENSO IBGE, 2017). 
Segundo Zardo (2012), as formas mais frequentes de comercialização nesta região são: a) venda direta do produtor na propriedade para o consumidor final; b) venda direta do produtor ao consumidor final em local fora da propriedade; c) centros de comercialização (criado via associação e cooperativas de agricultores familiares); d) programas institucionais (PAA - Programa de Aquisição de Alimentos; e, PNAE - Programa Nacional de Alimentação Escolar); e) Canais indiretos longos de comercialização (supermercados, cerealistas, indústrias, e centrais de abastecimento).

Este estudo tem por finalidade caracterizar os agricultores familiares que comercializam em feiras de produtores rurais nas cidades de Marechal Cândido Rondon, Toledo e Cascavel, pertencentes à região oeste do Estado do Paraná, tendo como premissa conhecer as principais características socioeconômicas e mercadológicas desses produtores. Mediante a caracterização dos produtores, 0 estudo tem por objetivo, analisar a utilização do comércio eletrônico como mercado alternativo e a intenção de sua expansão comercial, levando em consideração o mercado online. Os objetivos específicos avaliados foram: a) caracterizar os produtores familiares rurais que comercializam na feira do produtor; $b$ ) identificar $o$ uso das Tecnologias de Informação e Comunicação (TICs) por parte dos produtores; c) descrever alguns fatores que os produtores consideram importantes e os aspectos que consideram obstáculos para o uso do comércio eletrônico.

Nos últimos meses, o mundo tem vivenciado uma crise sanitária, a pandemia do Covid-19 (Corona Vírus), o que tem evidenciado, ainda mais, a relevância do comércio eletrônico, o qual vem se mostrado um forte aliado para todos os nichos mercadológicos, inclusive para a agricultura familiar. Muitos agricultores estão utilizando a internet para comercializar a sua produção e gerar renda. O Estado do Rio Grande do Sul, tem se destacado nos estudos e criação de plataformas para que os agricultores familiares possam escoar a produção, buscando nas vendas digitais, as alternativas para superar impactos durante a crise sanitária. (EMATER-RS, 2020; LOEBLEIN, 2020; AGROEMDIA, 2020).

No Paraná, segundo a Emater-PR (2020), o e-commerce já está disponível há alguns anos para os produtos agropecuários e também representa uma forte estratégia de comercialização para o agricultor familiar, principalmente, no período da crise sanitária. O trabalho de incentivo ao uso do comércio eletrônico está sendo realizado por meio dos profissionais de assistência aos agricultores, a fim de promover renda e segurança alimentar, além de ser um método para inibir a disseminação do vírus.

Para compreender o uso e entendimento por parte dos agricultores sobre as ferramentas tecnológicas, buscou-se referenciar os conceitos sobre inovação tecnológica e comércio eletrônico, para possibilitar uma abordagem de forma mais ampla acerca da inserção dos agricultores no mercado online. Quanto a descrição metodológica aplicada ao estudo, trata-se de uma pesquisa de campo, realizada nas feiras do produtor rural das cidades de Marechal Cândido Rondon, Toledo e Cascavel. Para responder as indagações, foi utilizado um questionário semiestruturado com a participação de 69 agricultores familiares e, posteriormente, os dados foram tabulados e processados utilizando-se o programa estatístico Statistical Package for the Social Sciences - SPSS versão 20. Em seguida, apresenta-se os resultados da pesquisa e as conclusões do trabalho. 


\section{Agricultura familiar frente às novas oportunidades de mercados}

A agricultura familiar é aquela em que a família é proprietária do bem e produz para seu autoconsumo, além de ter a possibilidade de comercializar a produção excedente, a fim de auferir renda (WANDERLEY, 2004). De forma complementar, Serenini e Malysz (2014) salientam que a agricultura familiar desempenha a função de produzir alimentos para atender o mercado interno. Romeiro (1998), caracteriza o agricultor familiar como aquele que possui acesso aos meios de produção e aos mercados e recorre a mão de obra familiar.

Abramovay (1992) define a agricultura familiar quanto à gestão, na qual a propriedade e a força de trabalho são constituídas por indivíduos que possuem um laço de sangue ou parentesco. Neves (2002), considera o agricultor familiar como aquele que administra seu estabelecimento rural; caracterizam-se neste quesito os assentados e agricultores de subsistência, pois estes buscam novas posições sociais por intermédio de políticas públicas.

$\mathrm{O}$ art. $3^{\circ}$ da Lei 11.326/2006 considera o agricultor familiar aquele que pratica atividades no meio rural que atendem as seguintes premissas:

I. Não detenha, a qualquer título, área maior do que quatro módulos fiscais;

II. Utilize predominantemente mão-de-obra da própria família nas atividades econômicas do seu estabelecimento ou empreendimento; III. Tenha percentual mínimo da renda familiar originária de atividades econômicas do seu estabelecimento ou empreendimento (da forma definida pelo Poder Executivo conforme Lei 12.512/2011);

IV. Dirija seu estabelecimento ou empreendimento com sua família (BRASIL, 2006, n. p.)

Graziano da Silva (1999) considera que o cenário atual da agricultura familiar, denominado por ele como "novo rural", constitui-se por múltiplas atividades agrícolas e não agrícolas, pois a agricultura familiar vai além da agropecuária e agroindústria, abrangendo também o artesanato e o turismo rural.

Por outro lado, Blum (2001), considera que a agricultura familiar está inserida num cenário em que as transformações ocorrem de forma acelerada. Contudo, o autor pondera que o Brasil a partir de 1970 passou a enfrentar algumas dificuldades de inserção no mercado, decorrentes da modernização agrícola. Ainda hoje, a agricultura familiar enfrenta diversos problemas que intrinsecamente não é capaz de sanar, sendo necessário o auxílio governamental por meio de políticas públicas eficientes que possam garantir a conservação, a continuação e a estabilidade da agricultura familiar perante a modernização agrícola.

Serenini e Malyz (2014) consideram que os maiores problemas da agricultura familiar estão relacionados à modernização agrícola, em especial, no que tange à pressão exercida pelos latifundiários, a decadência da sucessão familiar rural e a ausência de valorização e políticas públicas específicas. Com o processo de modernização agrícola, as tecnologias desenvolvidas para o meio rural contemplam apenas a minoria, ou seja, agricultores com alto poder aquisitivo; assim, as máquinas substituem a mão-de-obra humana e os trabalhadores, por sua vez, se deslocam à área urbana em busca de trabalho, culminando no êxodo rural. 
Para Fantineli et al. (2016), existem poucas políticas públicas voltadas à agricultura familiar; porém, as unidades familiares vista pelo processo de diversificação da produção com atividades ligadas ao turismo rural, agroindústria, feiras, entre outros mercados, conseguem permanecer no campo e dispor de renda.

Wanderley (2009) considera que agricultura familiar integrada ao mercado busca meios de produção e reprodução. O mercado está relacionado ao processo de procura e oferta de determinado produto. A procura advém pelo fato de as pessoas estarem dispostas a gastar por tal produto, levando em consideração o salário, a utilidade, a necessidade e os preços. Já a oferta é caracterizada pelos fatores de produção, clima, custos operacionais, regiões e, consequentemente, os preços praticados (SILVA; MARTINELLI, 2012).

Os mercados são responsáveis pela interação social entre produtores e consumidores. Para Schneider, et al. (2016), os mercados são espaços nos quais ocorrem as trocas e comercialização de bens e produtos, bem como, a interação por meio de diálogo e ações culturais. Os autores salientam que diante da vulnerabilidade econômica e social existente no meio rural, perante os mercados de commodities, surgem meios de desenvolvimento dos mercados alternativos, sendo:

[...] mercados institucionais, mercados para produtos agroecológicos, para produtos com especificidades (locais, étnicas, de processos produtivos, ligados a uma região), da venda de alimentos tradicionais casada com o turismo rural, de alimentos processados pelas agroindústrias familiares, entre outras alternativas que estão surgindo no país (SCHNEIDER, et al., 2016, p. 13).

Os agricultores familiares em grande parte estão inseridos nos chamados circuitos curtos (CC). Para Guzzatti, et al. (2014), os CC são meios de comercialização de produtos agrícolas com finalidade de aproximar os produtores e consumidores. Darolt, et al. (2013), realizaram um estudo sobre a diversidade dos mercados alternativos com base nos circuitos curtos entre Brasil e França, conforme Figura 1.

Figura 1 - Tipos de Circuitos Curtos de Comercialização de Produtos Ecológicos no

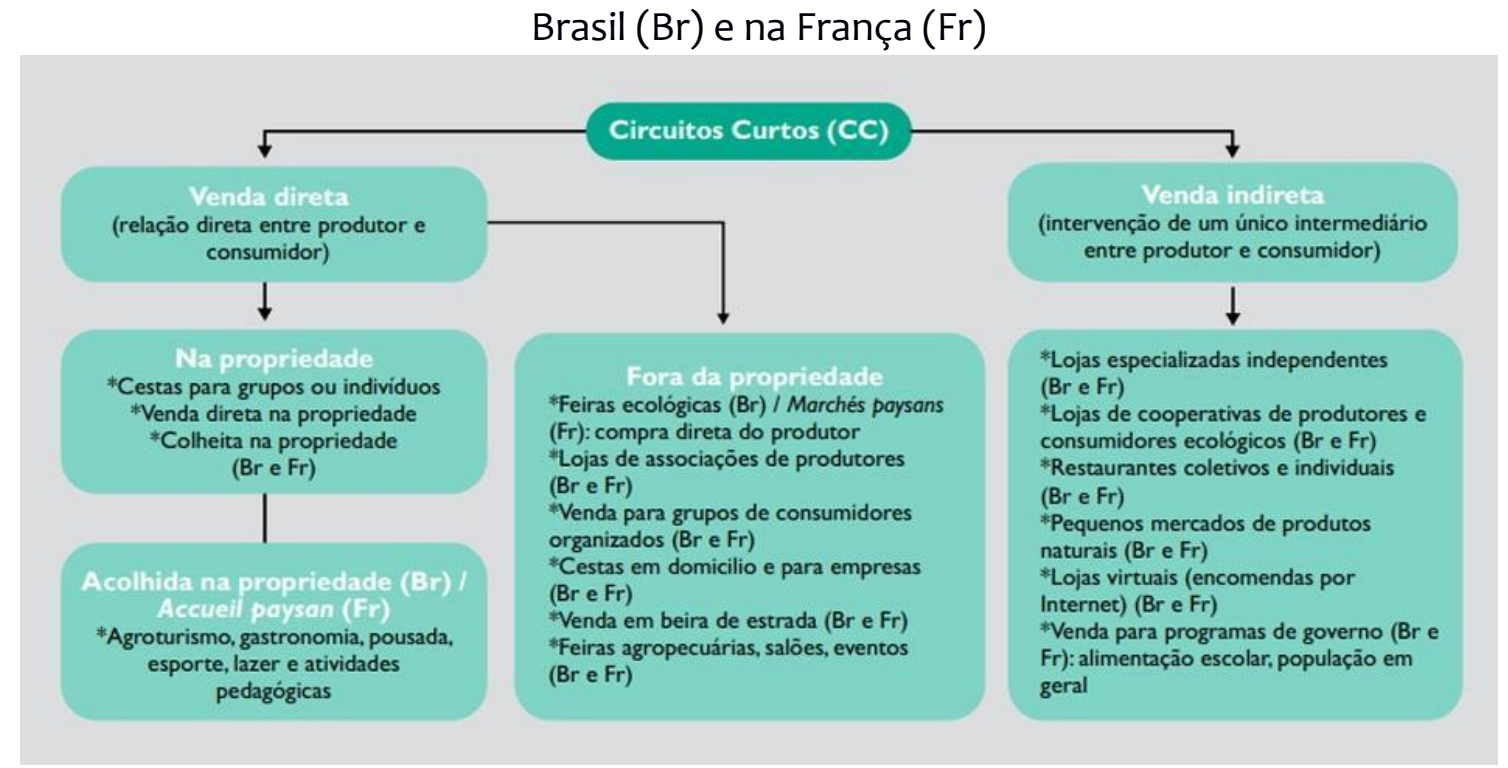

Fonte: Darolt, et al. (2013). 
As feiras do produtor e as cestas a domicílios são consideradas pelos autores como venda direta, ou seja, a comercialização não envolve intermediários. No caso das cestas a domicílio, estas normalmente possuem três formatos: a) cestas pequenas, que variam de quatro a seis itens; b) cestas médias, que variam de sete a dez itens; e, c) cestas grandes, que variam de onze a dezesseis itens. As cestas são entregues comumente uma vez na semana. Já a comercialização em programas do governo pode ser caracterizada como venda direta ou indireta, variando de acordo com o processo comercial. Pode ser o próprio produtor que efetua o cadastro nos programas e realiza as entregas, ou os produtores entregam os produtos, por exemplo, a uma cooperativa cadastrada nos programas governamentais, a qual realiza as entregas, sendo considerada uma intermediadora (DAROLT, et al. 2013).

A região oeste do Estado do Paraná conta com 32.152 estabelecimentos rurais da agricultura familiar, que comercializam os produtos por meio de cinco formas diferenciadas conforme especifica Zardo (2012):

a) venda direta do produtor na propriedade para o consumidor final: os produtos são entregues ao consumidor na residência ou o cliente vai até a propriedade do agricultor retirar o pedido.

b) venda direta do produtor ao consumidor final em local fora da propriedade: a comercialização dos produtos é realizada à beira de movimentadas rodovias; e, em feiras municipais denominadas de feira livre e/ou do produtor rural.

c) centros de comercialização (criado via associação e cooperativas de agricultores familiares): a comercialização é realizada em um ponto de venda localizado normalmente no centro de pequenas cidades; também é comum a venda dos produtos oriundos da agricultura familiar para cooperativas leiteiras e agropecuárias.

d) programas institucionais (PAA - Programa de Aquisição de Alimentos; e, PNAE - Programa Nacional de Alimentação Escolar): o PAA foi instituído pela lei Federal 10.696/2003 com a intenção do combate à fome, promovendo o acesso aos alimentos as populações em situação de insegurança alimentar, além de proporcionar a inclusão social e econômica no campo por meio do fortalecimento da agricultura familiar. Nesse programa, o governo realiza a compra e os alimentos são destinados a entidades da rede socioassistencial, como restaurantes populares, cozinhas comunitárias, escolas, creches, asilos e hospitais públicos. Já o PNAE, foi implantado pelo decreto 37.106/31/03/1995, permite a transferência de recursos da União aos Municípios para a alimentação de alunos de toda a educação básica.

e) Canais indiretos longos de comercialização (supermercados, indústrias, e central de abastecimentos): a comercialização em supermercados é possível graças a parceria entre o Governo do Estado do Paraná e a APRAS (Associação Paranaense de Supermercados) que visa dar condições de acesso ao grande varejo, permitindo a comercialização de produtos agroindustrializados pelas famílias incluídas no Programa Fábrica do Agricultor ${ }^{1}$. Já a comercialização em indústrias ocorre pela compra de produtos oriundos da agricultura familiar para o processamento do alimento visando o consumidor final. Essa prática ocorre, principalmente, em indústrias de transformação de leite. Quanto a central de abastecimentos, essa visa sanar os problemas de abastecimento nos principais centros urbanos de concentração populacional. Em 1978 foi implantada a CEASA (Central de

\footnotetext{
${ }^{1}$ Programa do Estado específico para produtos industrializados pelo agricultor familiar.
} 
Abastecimento do Paraná) em Foz do Iguaçu, e em 1979 em Cascavel. Em Cascavel são 45 agricultores familiares cadastrados na unidade (CEASA, 2020).

\subsection{O mercado online como inovação tecnológica}

O uso da tecnologia na agricultura familiar, segundo Souza Filho et al. (2004), não é atrasado (como essa classe normalmente é tachada), quando relacionado à inovação tecnológica. Os autores salientam que é possível perceber a assídua e crescente participação dos produtores organizados em sociedade e/ou cooperativas no processo de desenvolvimento tecnológico.

Souza Filho et al. (2011), consideram que a adoção e a difusão tecnológica na agricultura familiar dependem de variáveis como tamanho da propriedade, riscos, incertezas, capital humano, forma de domínio sobre a terra (arrendamento, parceria, direitos de propriedade), disponibilidade de crédito, trabalho e outros insumos. Por outro lado, a introdução das tecnologias na agricultura familiar carece de incentivo por meio das políticas públicas, disponibilidade e acesso à informação, serviços de assistência técnica e extensão rural. Todas essas características afetam a decisão de adotar as inovações tecnológicas, sendo algumas variáveis não controladas pelos produtores, ocasionando insegurança quanto à implantação.

Lima e Wilkinson (2002) consideram que para o agricultor familiar ter acesso aos mercados é necessário, além das competências intrínsecas, buscar novos conhecimentos e práticas, a fim de tornar-se um diferencial. Para que o produtor familiar seja competitivo nos mercados, faz-se necessária a implantação de "alternativas tecnológicas" adaptadas aos agricultores que não produzem em larga escala, bem como, introduzir a produção diversificada, sendo essa uma estratégia de desenvolvimento local sustentado pelo "processo de gestão, organização da produção e de promoção da diferenciação de produtos", gerando oportunidades aos produtores familiares (MEDEIROS, et al., 2002, p. 24).

A internet é um meio de inovação tecnológica que, de acordo com Cohen (2002), possibilita o acesso às informações e os agricultores têm a capacidade de acelerar a velocidade de comercialização, além de auxiliar na redução dos custos, aumentar a competência econômica e melhorar a eficiência. Pimentel (2002), considera a internet como um meio de fazer novos negócios. Angehrn (1997) salienta que a internet criou um novo meio de interação entre produtores e consumidores por meio do comércio eletrônico.

Andrade (2001, p. 13) define o comércio eletrônico como "a aplicação de tecnologias de comunicação e informação compartilhadas entre as empresas, procurando atingir seus objetivos". O autor considera quatro tipos diferentes de comércio eletrônico, fortemente presentes no cotidiano. Sendo:

a) Business to Business ( $B 2 B)$ : Comercialização praticada entre fornecedores e empresas; nesse tipo de comércio é realizada compra e venda de produtos, informações e serviços por meio da internet;

b) Business to Consumer (B2C): Comercialização praticada entre empresas e consumidor final, envolvendo atividades de venda de produtos e prestação de serviço por meio da internet. Nesse tipo de comércio existem sites específicos denominados lojas virtuais, 
que por muitas vezes cedem espaço apenas ao mercado online sem interesse no mercado físico;

c) Consumer to Consumer ( $\mathrm{C} 2 \mathrm{C})$ : A comercialização se desenvolve entre pessoas físicas na internet, ou seja, as vendas e compras são realizadas de um consumidor final para outro, muito comum seu uso em marketplaces.

d) Government to Citizen ( $\left.\mathrm{G}_{2} \mathrm{C}\right)$ : Comércio entre o governo e consumidor através da internet. São exemplos os pagamentos de impostos, multas e tarifas por meio de um portal eletrônico do governo, o qual oferece orientação e serviços aos cidadãos.

Bodini e Zanoli (2011) consideram que o comércio eletrônico é um potencial de acesso aos mercados, haja em vista que por meio da internet há a redução dos obstáculos geográficos, permitindo atingir mais pessoas. Ademais, o comércio eletrônico é uma oportunidade de promover a organização social da produção, seja por meio de cooperativas ou de associações.

Darolt et al. (2016) realizaram um estudo comparativo entre Brasil e França relacionado aos mercados alternativos. Perante o uso do comércio eletrônico as vendas por cestas a domicílio, conhecidas como delivery, estão bem difundidas na França. No Brasil, as cestas vêm ganhando espaço pela praticidade e por apresentarem menores preços se comparados aos supermercados. Já as vendas em lojas virtuais, que estão se constituindo em ambos os países e são consideradas sinônimos de crescimento, nem sempre são consideradas como circuitos curtos, mas se apresentam como alternativas diante da facilidade, comodidade e preço comparado aos mercados e atendendo as necessidades dos consumidores frente à vida moderna.

Esse tipo de comércio tem se tornado mais evidente mediante a pandemia da Covid-19 e vem produzindo grandes impactos, não somente em questões de ordem sanitária, mas também na política, na cultura, na sociedade e na economia. $\mathrm{Na}$ agricultura familiar a repercussão não é diferente. Sem conseguir entregar os alimentos em supermercados e comercializá-los nas feiras os produtores estão acumulando prejuízos. No entanto, a alternativa de comércio eletrônico tem minimizado os impactos financeiros.

Neste sentido, a CNA (Confederação da Agricultura e Pecuária do Brasil) em parceria com o SENAR (Serviço Nacional de Aprendizagem Rural) desenvolveu uma plataforma virtual para conectar os produtores rurais e os consumidores, a fim de, garantir o escoamento da produção e gerar renda aos agricultores (CNA, 2020).

O $41^{\circ}$ relatório Webshoppers (2020) analisou o período de 19 de março à 27 de abril de 2020 e constatou que o e-commerce teve um acréscimo de 48,3\% no faturamento, passando de $\mathrm{R} \$ 5,7$ para $\mathrm{R} \$ 8,4$ bilhões. Com a necessidade de isolamento, a fim de diminuir e/ou não agravar o risco de contágio do coronavírus, as compras realizadas pelo comércio eletrônico contribuíram $45 \%$ no número de pedidos. O setor de alimentos tem se destacado nesse período de isolamento, obtendo um crescimento de $13 \%$ no período de fevereiro até o final de abril.

Desta forma, considera-se que o mercado online se apresenta como uma excelente alternativa para ampliar as transações comerciais geradas na agricultura familiar, com a possibilidade de ampliar os canais de distribuição, bem como proporcionar facilidades e comodidade ao consumidor e, com isso, ampliar a renda do produtor. 


\section{Material e métodos}

O presente estudo é delineado pela pesquisa de campo, e para responder o questionamento que orientou a realização desse trabalho, optou-se pelo emprego de métodos mistos, nesse sentido, a natureza metodológica está pautada pelas abordagens qualitativas e quantitativas. $O$ estudo foi realizado nos Municípios de Marechal Cândido Rondon, Toledo e Cascavel, localizados na região oeste do Estado do Paraná conforme Figura 2.

Figura 2 - Localização Geográfica dos Municípios de Marechal Cândido Rondon, Toledo e Cascavel.

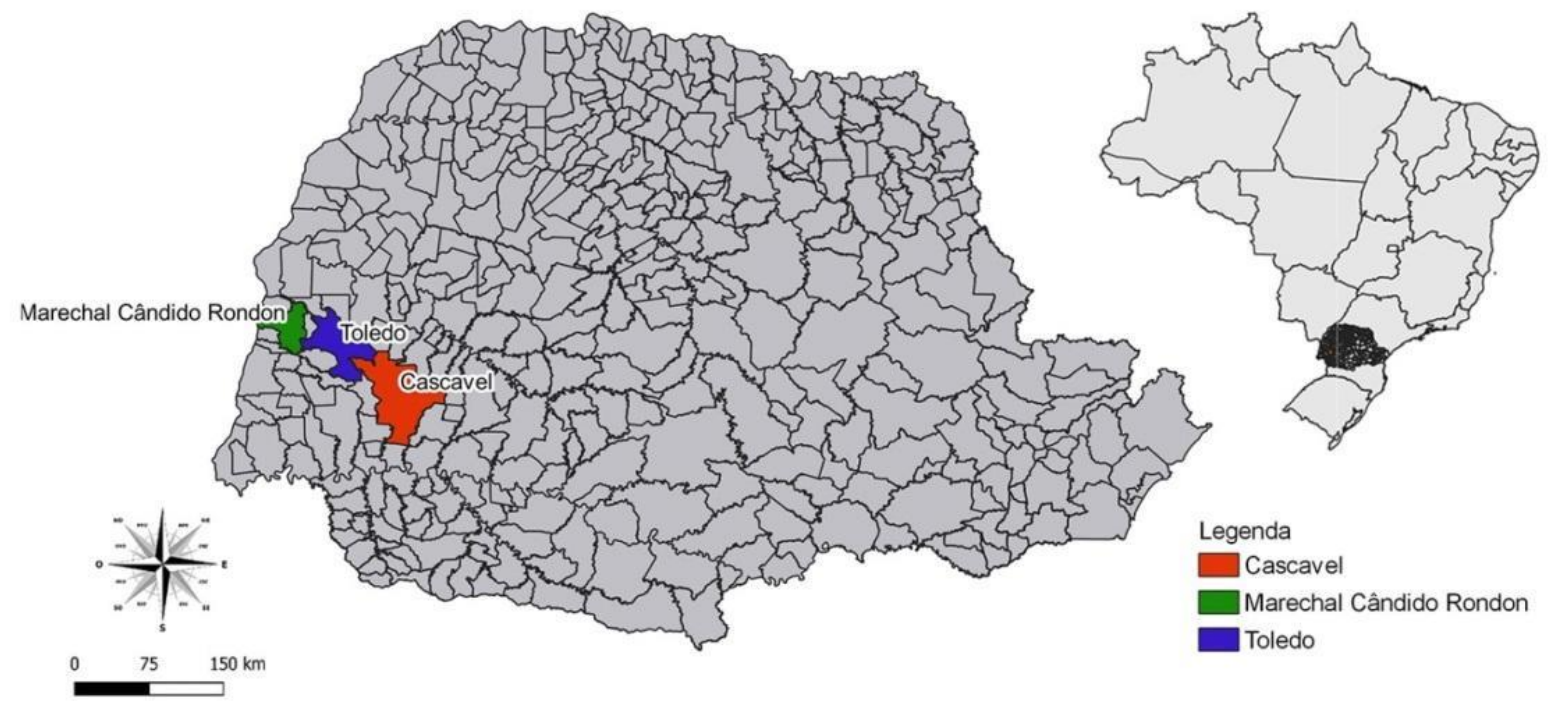

Nota: UTM - Datum SIRGAS 2000, Fuso 22S

Fonte: Elaborado pela autora (2019).

O estudo contou com uma amostra de 69 feirantes com vínculo à agricultura familiar. Para calcular o tamanho da amostra, foi utilizada a fórmula de amostragem citada por Mattar (1996, p. 220), para uma população finita.

$$
\text { Q }=\frac{N \cdot Z^{2} \cdot p \cdot q}{E^{2} \cdot N+Z^{2} \cdot p \cdot q}
$$

Em que:

$\mathrm{n}=$ tamanho da amostra;

$\mathrm{N}=$ tamanho da população;

$Z=$ valor padrão determinado pelo nível de confiança. Para o nível de confiança de 95\%, Z=1,96;

$\mathrm{p}=$ proporção de ocorrência da variável em estudo na população $(0,5)$;

$q=$ proporção de não-ocorrência da variável em estudo na população (q= 1- p);

$\mathrm{E}=$ erro máximo admitido $(0,05)$.

$$
\begin{gathered}
\mathrm{n}=84 \cdot 1,96^{2} \cdot(0,5 \cdot 1-0,5) /\left(0,05^{2} \cdot 84+1,96^{2}\right) \cdot(0,5 \cdot 1-0,5) \\
\mathrm{n}=322,6944 \cdot 0,25 / 0,0025 \cdot 84+3,8416 \cdot 0,25
\end{gathered}
$$




$$
\begin{gathered}
n=80,6736 / 0,21+0,9604 \\
n=68,95
\end{gathered}
$$

Os Municípios de Marechal Cândido Rondon, Toledo e Cascavel possuem respectivamente, 13, 48 e 95 feirantes no total. Foram entrevistados 13 feirantes na cidade de Marechal Cândido Rondon, 24 feirantes na cidade de Toledo e 47 feirantes na cidade de Cascavel, todos eles possuem vínculo com o meio rural.

Desse modo, para realizar o cálculo amostral foi considerado um universo de 84 agricultores familiares. O valor de erro amostral utilizado foi de $5 \%$ constituindo uma amostra de 69 agricultores. Para a coleta de dados utilizou-se um questionário semiestruturado, que abordou dados socioeconômico, de produtividade, tecnológicos, e mercadológicos, aplicado aos agricultores familiares que comercializam os seus produtos nas feiras dos respectivos municípios. As coletas de dados foram realizadas no período de 3 de dezembro de 2018 a 30 de janeiro de 2019.

Posteriormente a aplicação dos questionários, os dados foram tabulados e processados utilizando-se o programa estatístico Statistical Package for the Social Sciences - SPSS versão 20. Os resultados foram calculados por meio do teste não paramétrico Kruskal Wallis, após as variâncias não apresentarem homogeneidade e normalidade na distribuição. O teste foi escolhido, a fim de verificar se as variáveis analisadas entre os produtores rurais dos municípios em estudo possuem a mesma distribuição, ou seja, saber se em determinadas variáveis os produtores rurais possuem as mesmas características ou não. Para os dados que não puderam ser analisados sob a ótica do teste elaborou-se tabelas de frequência para a representação dos resultados obtidos.

Com este estudo foi possível quantificar a composição dos produtores rurais da agricultura familiar nos Municípios de Marechal Cândido Rondon, Toledo e Cascavel. O estudo está relacionado tanto a formação como produtor rural e a comercialização na feira do produtor rural dos respectivos municípios, quanto à utilização do comércio eletrônico e a intenção de expansão comercial.

\section{Resultados e discussão}

O estudo apresenta que dos 69 agricultores analisados, 46 realizam vendas pelas redes sociais, desses, 11 comercializam em sites do tipo marketplace, sendo que 23 agricultores, apenas, comercializam os produtos no mercado físico. Conceição e Freitas (2018), consideram que o uso da internet facilita a comunicação entre produtor e consumidor, além de contribuir com o acesso de informação sobre a forma apropriada de inserir-se nos mercados, bem como a inclusão de produtos, com a finalidade de ganhar visibilidade por meio da divulgação em sites e redes sociais.

Quando comparado os agricultores que comercializam pelas redes sociais e o nível de escolaridade que possuem, verifica-se que 32 completaram o ensino fundamental, 36 concluíram o ensino médio e 1 tem ensino superior completo. De acordo com Lacki (1998), o nível de escolaridade e formação profissional aumenta a capacidade de obtenção e processamento de informação e habilidades para uso de 
técnicas e métodos de gerenciamento, como forma de contribuir para o êxito do empreendimento.

Quanto à renda mensal com as vendas na feira do produtor, 33,3\% dos participantes da pesquisa recebem até dois salários mínimos e, 66,7\% têm renda de três salários mínimos ou mais. Aqueles que comercializam em sites ou redes sociais, não souberam precisar o montante que complementa a renda. Luciano (2017), confirma em seu estudo a importância na comercialização em feiras, sendo que a renda varia entre $10 \%$ a $75 \%$ na complementação da renda mensal dos produtores rurais familiares.

De acordo com Brandão (2012), a renda empreendida na feira apresenta-se muitas vezes baixa, inferior a um salário mínimo. Porém, quando considerada a produção para o próprio consumo e a utilização dos rejeitos e sobras para a alimentação animal, os gastos diminuem e, consequentemente, agrega à renda familiar. $O$ autor considera que o custo de produção dos agricultores familiares é baixo, pois a maioria utiliza a adubação orgânica e grande parte do valor arrecadado se converte em lucro.

Quanto ao tamanho da propriedade, $76,8 \%$ dos entrevistados possuem até 10 hectares, os demais têm 11 hectares ou mais. A produção dos agricultores familiares comercializadas nas feiras dos produtores rurais são diversificadas (Tabela 1). Para Gomes et al. (2014), a diversificação produtiva é uma estratégia para a geração de renda, pois, considerando os períodos sazonais, os agricultores familiares não estão submissos à monocultura e, portanto, garantem a renda ao longo do ano. A Tabela 1 apresenta a quantidade de produtores que comercializam os produtos.

Tabela 1 - Variedades de produtos comercializados nas Feiras dos Produtores Rurais

\begin{tabular}{lr}
\hline \multicolumn{1}{c}{ PRODUTO } & FREQ. $\left(\mathbf{N}^{\circ}\right)$ \\
\hline Hortaliças e legumes & 37 \\
Frutas & 17 \\
Doces, mel, geleia, melado & 17 \\
Ovos & 15 \\
Carnes e embutidos & 13 \\
Panificados e derivados & 13 \\
Lácteos e derivados & 09 \\
Bebidas & 08 \\
Lanches & 07 \\
Mandioca & 04 \\
\hline
\end{tabular}

Fonte: Dados da Pesquisa (2019).

Os produtores que vendem por meio dos sites, comercializam produtos com prazos de validade mais longa, como doces, mel, geleia e bebidas. Quanto à utilização das redes sociais para fins comerciais todos os produtos apresentados na tabela 1, são comercializados no Facebook ${ }^{\circledR}$ e ou Instagram ${ }^{\circledR}$, sendo muitas vezes negociados pelo aplicativo de mensagem WhatsApp ${ }^{\circledR}$.

Segundo Bonfim et al. (2015), o uso das Tecnologias de Informação e Comunicação (TIC) são indispensáveis no desenvolvimento de todos os setores econômicos, inclusive no meio rural. No presente estudo, 68 produtores têm acesso 
à internet e a utilizam por meio de Smartphones e/ou computadores, apenas um entrevistado apontou não ter acesso a internet e não possuir equipamentos de informática.

Os produtores avaliaram os principais motivos que consideram importantes para vender na internet, além de os principais motivos que são considerados obstáculos para a comercialização, conforme Gráfico 1 e 2 respectivamente.

Gráfico 1 - Principais motivos que os produtores consideram importantes para vender pela internet

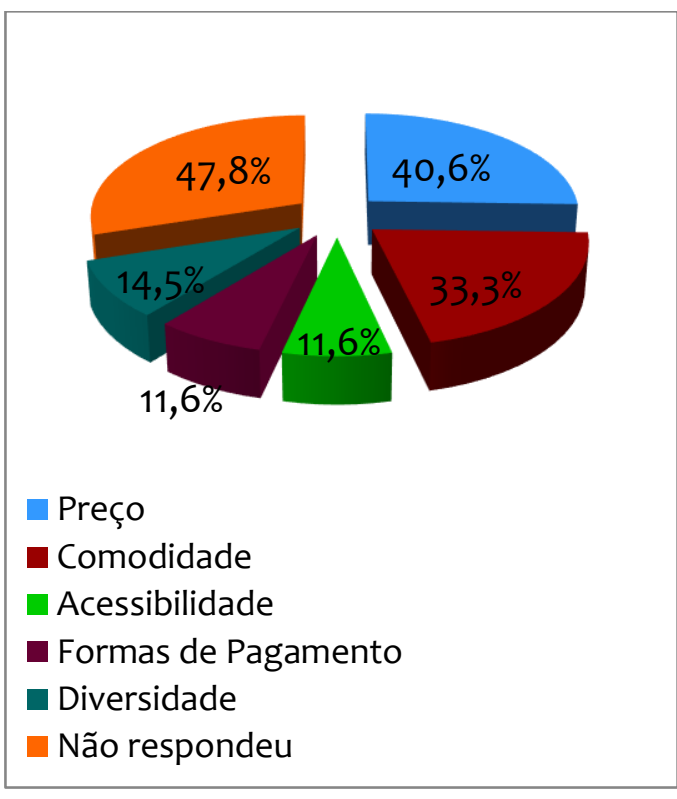

Fonte: Dados da Pesquisa (2019).
Gráfico 2 - Principais motivos que os produtores consideram como restrição para vender pela internet

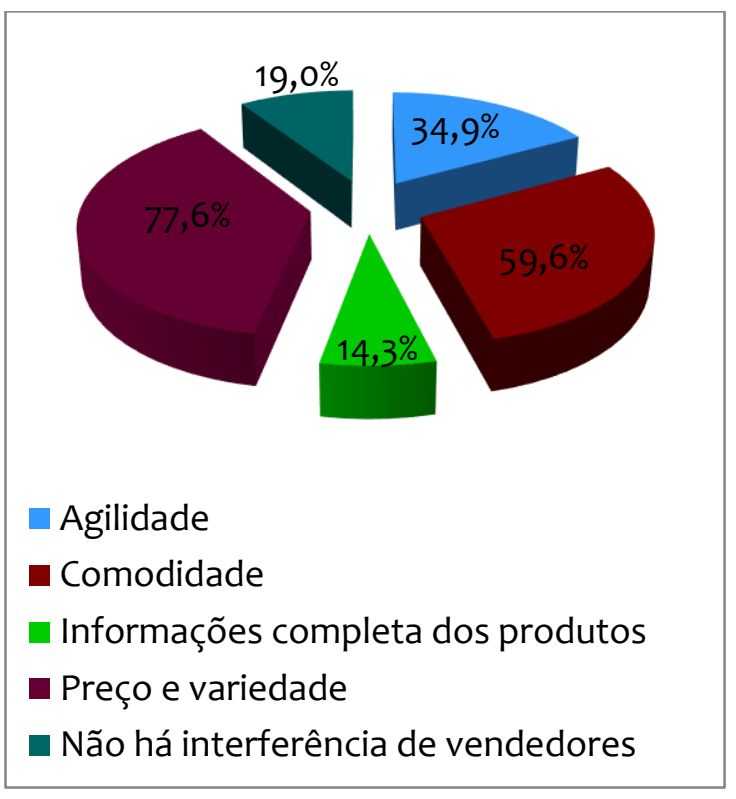

Fonte: Dados da Pesquisa (2019).

Tanto os produtores que comercializam pelas redes sociais ou em sites, quanto os que têm intenção em comercializar pela internet, mas ainda não o fazem, percebem como principais motivos para comercializar no meio online a demanda e a comodidade. Esses consideram que a procura por pedidos em redes sociais, principalmente, no WhatsApp ${ }^{\circledR}$, tem aumentado. Os produtores também consideram que seria mais cômodo utilizar as redes sociais ou sites, inclusive para comercialização local em que pudessem estipular um determinado dia para efetuar as entregas.

Bodini e Zanoli (2011) consideram que o comércio eletrônico apresenta alguns benefícios aos agricultores familiares. Para os autores, a troca de informação é rápida e precisa, possibilita a apresentação das informações sobre os produtos e os preços de modo ágil e reduz ou elimina os custos de transação.

Contudo, os agricultores consideram que para implantar o comércio eletrônico na agricultura familiar é necessário obter treinamento e capacitação para o melhor desenvolvimento do negócio.

Para Dutra (2009) o desenvolvimento da organização está relacionado ao treinamento e capacitação das pessoas envolvidas nas atividades organizacionais, a fim de preparar-se para eventuais mudanças no mercado, além de melhor compreender as inovações tecnológicas presentes. 
Quando perguntado aos produtores sobre a intenção em expandir o modo de comercialização, 52 deles responderam que possuem interesse em novos mercados, enquanto 17 se dizem satisfeitos com a participação nos mercados em que estão inseridos. Porém, quando perguntados sobre a intenção em comercializar os produtos pela internet, 59 produtores consideram a hipótese de vender os produtos em redes sociais, sites ou outros meios online possíveis. Sendo que 10 entrevistados têm preferência somente pelo mercado físico. Abramovay (1992), afirma que para a construção do desenvolvimento rural e a erradicação da pobreza no campo é necessário investir na agricultura familiar e, para isso, é necessário melhorar a inserção dos produtores no mercado a fim de torná-los ainda mais competitivos. Balsadi (2001) acrescenta que no meio rural há uma multiplicidade de mercados, porém, são necessários projetos e políticas que os tornem efetivos.

Além disso, os produtores puderam responder de forma múltipla a qual/ais produtos que comercializam ou desejariam comercializar em redes sociais, sites ou outros tipos de comércio online, conforme Tabela 2.

Tabela 2 - Produtos que os agricultores familiares comercializam ou desejam

\begin{tabular}{lr}
\multicolumn{2}{c}{ Comercializar na internet } \\
\hline PRODUTOS & FREQ. $\left(\mathbf{N}^{\circ}\right)$ \\
\hline Dortaliças e legumes & 30 \\
Doces, mel, geleia & 12 \\
Panificados e derivados & 11 \\
Carnes e embutidos & 10 \\
Frutas & 10 \\
Ovos & 9 \\
Lácteos e derivados & 7 \\
Bebidas & 7 \\
Lanches & 3 \\
Mandioca & 2 \\
\hline Fonte: Dados da pesquisa (2019). &
\end{tabular}

Os agricultores familiares que comercializam nas feiras do produtor rural possuem um mix diversificado de produtos e, para uma possível comercialização pelos canais de venda da internet, a maior parte deles demonstraram interesse em vender hortaliças e legumes, seguido de doces, mel, geleia, panificados e derivados, entre outros produtos.

Com o propósito de saber se os produtores rurais possuem as mesmas características, foram analisadas as variáveis socioeconômicas dos produtores, realizando uma comparação entre os municípios em estudo, conforme Tabela 3. 
Tabela 3 - Síntese dos resultados da comparação das variáveis socioeconômicas dos produtores rurais entre os municípios de Marechal Cândido Rondon, Toledo e Cascavel

\begin{tabular}{lr}
\hline VARIÁVEL & RESULTADO (P>z) \\
\hline Escolaridade & $0,532^{*}$ \\
Área da propriedade em hectares & $0,735^{*}$ \\
Renda proveniente da propriedade & $0,722^{*}$ \\
Renda proveniente da feira & $0,025^{*}$ \\
Número de filhos que residem e trabalham na propriedade & $0,121^{*}$ \\
Número de pessoas que trabalham na propriedade & $1,000^{*}$ \\
\hline
\end{tabular}

Hipótese: Não há diferença entre os produtores dos municípios em estudo.

$\mathrm{P}=$ Valor ou Probabilidade de Significância

Nota* Significativos a $5 \%(z)$

Fonte: Dados da Pesquisa (2019).

O teste apresenta que somente a variável renda proveniente da feira obteve diferenças significativas, ou seja, quando comparada a receita dos produtores rurais entre os municípios, o rendimento é diferente de um município para outro. Portanto, rejeita-se a hipótese para essa variável. Esse resultado pode ser proveniente da disparidade entre o número de habitantes residentes em cada um dos municípios que integram a pesquisa. Para as demais variáveis, o teste não apresenta evidências estatísticas suficientes para afirmar que os produtores rurais possuem diferenças significativas perante as variáveis consideradas, portanto, não se rejeita a hipótese.

Na sequência, algumas características sociais e comerciais dos produtores rurais foram comparadas mutuamente entre todos os entrevistados, conforme Tabela 4.

Tabela 4 - Síntese dos resultados da comparação das características entre os produtores rurais nos municípios de Marechal Cândido Rondon, Toledo e Cascavel

\begin{tabular}{lr}
\hline VARIÁVEL & RESULTADO (P>z) \\
\hline Comparação escolaridade x Utilização de redes sociais & $0,394^{*}$ \\
Comparação idade x Utilização redes sociais & $0,283^{*}$ \\
Comparação idade x Escolaridade & $0,435^{*}$ \\
\hline
\end{tabular}

Hipótese: Não há diferença entre os produtores dos municípios em estudo.

$\mathrm{P}=$ Valor ou Probabilidade de Significância

Nota* Significativos a $5 \%(z)$

Fonte: Dados da Pesquisa (2019).

O teste não apresenta evidências estatísticas suficientes para afirmar que os produtores rurais possuem diferenças significativas em face das variáveis consideradas.

\section{Considerações Finais}

O estudo mostrou que a quantidade de agricultores que têm acesso à internet e utilizam equipamentos de informação e comunicação é relevante, o que revela que as pessoas no meio rural possuem oportunidades e são viabilizadas com 
acessos aos meios de comunicação. O estudo apontou que o número de agricultores que comercializam em redes sociais ou sites é significativa. Isso significa que a procura pelos produtos da agricultura familiar por meio da internet é uma condição favorável para a implantação do mercado eletrônico, considerando que o mercado online é uma oportunidade de ampliação da demanda. Outro fator que pode estar relacionado à utilização das redes sociais e sites para a comercialização é a quantidade de produtores que completaram o ensino médio.

Os produtores que vendem por sites comercializam produtos com prazos de validade mais longa, dentre eles destacam-se os doces, mel, geleia e bebidas. Portanto, para os demais produtos sugere-se a elaboração de cestas a serem entregues a domicílio em um dia da semana a qual os consumidores podem adquirir por meio do próprio site, sendo que este ofertaria uma diversidade de formas de pagamento. Por meio de redes sociais, os pagamentos podem ser realizados por transferência bancária, pagamento à vista ou com o uso do código QR code ${ }^{\circledR}$.

No comércio eletrônico há duas formas mais utilizadas para o processo de comercialização. A primeira refere-se a C2C, onde a comercialização é realizada entre duas pessoas físicas, consumidoras finais, sem intermediação de uma empresa. Nesse tipo de comércio online, o vendedor não possui uma plataforma específica de site, mas sim, publica seus anúncios em plataformas de marketplaces, nas quais o vendedor paga uma porcentagem de renda à plataforma contratada, a fim de custear os serviços fornecidos e obter um lucro.

A segunda forma mais utilizada é a B2C, cuja comercialização faz-se entre empresa e consumidor final, nesse caso, a empresa possui o site próprio. Algumas plataformas possuem custo zero e outras mais desenvolvidas cobram um aluguel pelo seu uso. Nesse tipo de site, é necessária a utilização de intermediadores de pagamento e alguns cobram uma porcentagem de renda, a fim de custear os serviços prestados e angariar lucro.

Conclui-se que o comércio eletrônico é uma alternativa de mercado, diante da utilização frequente das redes sociais para a comercialização, a qual faz parte das características do comércio eletrônico. Além de ser uma possibilidade de obtenção de renda, visto que os agricultores declaram o aumento da procura de produtos pelas redes sociais e aplicativos de mensagens. Os resultados têm como ponto negativo a insuficiência de estoque para atender a possível demanda, mas que podem ser ajustadas de acordo com a organização familiar perante a frequência de pedidos.

\section{REFERÊNCIAS}

ABRAMOVAY, R. Paradigmas do capitalismo agrário em questão. São Paulo: Hucitec/Unicamp, 1992.

AGROEMDIA. App ajuda agricultores familiares do litoral norte gaúcho a vender produção. 2020. Disponível em: https://agroemdia.com.br/2020/05/03/app-ajudaagricultores-familiares-do-litoral-norte-gaucho-a-vender-producao/. Acesso em: 05 jun. 2020.

ANDRADE, R. Guia Prático do E-commerce. 1. ed. São Paulo: Angra, 2001. 
ANGEHRN, A. A. The Strategic Implications of the Internet. Proceedings from the 5th European Conference on Information Systems, Cork, Ireland, v. 3, 1997, p. 11631173.

BALSADI, O. V. Mudanças no meio rural e desafios para o desenvolvimento sustentável. São Paulo em Perspectiva, v. 15, n. 1, Jan./Mar. São Paulo, 2001, p. 155165.

BLUM, R. A agricultura familiar: um estudo preliminar da definição, classificação e problemática. IN: TEDESCO, J. C. (org.). A agricultura familiar: realidades e perspectivas. 3. ed. Passo Fundo: UPF, 2001, p. 57-104.

BODINI, A.; ZANOLI, R. Competitive Factors of the Agro-Food E-commerce. Journal of Food Products Marketing, v. 17, 2011, p. 241-260.

BONFIM, E. B., et al. Análise das TIC acessadas por produtores rurais familiares da Associação de Bananicultores de Tupã/SP. IN: XXVII Congresso de Iniciação Científica da Unesp, Tupã, SP, 2015.

BRANDÃO, A. A. Produção e comercialização de hortaliças em feiras livres na microrregião de Januária. Dissertação (Mestrado em Ciências Agrárias) Universidade Federal de Minas Gerais, 2012. Montes Claros, MG, 2012. $92 f$.

BRASIL. Lei n. 11.326 de 24 de Julho de 2006. Estabelece as diretrizes para a formulação da Política Nacional da Agricultura Familiar e Empreendimentos Familiares Rurais. Brasília, 2006.

BUAINAIN, A. M., et al. Agricultura familiar e o novo mundo rural. Sociologias, Porto Alegre, v. 5, n. 10, jul.-dez. 2003, p. 312-347.

CEASA. Institucional - Unidades Atacadistas. 2020. Disponível em: http://www.ceasa.pr.gov.br/modules/conteudo/conteudo.php? conteudo=3. Acesso em 06 jun. 2020.

CNA - CONFEDERAÇÃO DA AGRICULTURA E PECUÁRIA DO BRASIL. Sistema CNA/Senar lança plataforma para estimular venda de produtos do agro. 2020. Disponível em: https://www.cnabrasil.org.br/noticias/sistema-cna-senar-lancaplataforma-para-estimular-venda-de-produtos-do-agro. Acesso em: 5 jun 2020.

COHEN, M. F. Alguns aspectos do uso da informação na economia da informação. Ciência da Informação, Brasília, v. 31, n. 3, set.-dez. 2002, p. 26-36.

CONCEIÇÃO, A. F.; FREITAS, A. F. Cadeias Curtas e Internet: Utilização de estratégias de comunicação na conexão entre consumidores e produtores. IN: VIII Simpósio sobre Reforma Agrária e Questões Rurais - Terra, trabalho e lutas no século XXI: projetos em disputa, 2018, Araraquara, SP, 2018. 
DAROLT, M. R., et al. A diversidade dos circuitos curtos de alimentos ecológicos: ensinamentos do caso brasileiro e francês. Agriculturas, v. 10, n. 2, junho, 2013.

DAROLT, M. R., et al. Redes alimentares alternativas e novas relações produçãoconsumo na França e no Brasil. Ambiente e Sociedade, v. 9, n. 2, São Paulo, abr-jun, 2016, p. 1-20.

DUTRA, J. S. Gestão de pessoas: modelo, processos, tendências e perspectiva. São Paulo: Atlas, 2009.

EBIT/ NIELSEN. WEBSHOPPERS. 41. ed. Santana de Parnaiba: Ebit/ Nielsen, 2020. Disponível em: https://www.ebit.com.br/webshoppers. Acesso em: 05 jun. 2020.

EMATER-PR. E-comemrce pode ser estratégia de comercialização para o agricultor familiar frente à covid-19. 2020. Disponível em:

http://www.emater.pr.gov.br/modules/noticias/article.php? storyid=5812\&tit=eCommerce-pode-ser-estrategia-de-comercializacao-para-o-agricultor-familiar-frentea-COVID-19. Acesso em: 5 jun. 2020.

EMATER-RS. Cooperativas de Erechim disponibilizam compras online e delivery de alimentos da agricultura familiar. 2020. Disponível em:

http://www.emater.tche.br/site/social/detalhe-comunicados.php. Acesso em: 05 jun. 2020.

ESTEVAM, D. O., et al. Os desafios da inserção formal de produtos da agricultura familiar no mercado. Redes, Santa Cruz do Sul: Universidade de Santa Cruz do SUI, v.23, n. 1, jan.-abr. 2018, p.263-281.

FANTINELI, D. G., et al. A agricultura familiar e suas estratégias de sobrevivência. IN: I Seminário Nacional de Desenvolvimento Regional, 2016, Taquara, RS. Anais I

Seminário Nacional de Desenvolvimento Regional, 2016.

GOMES, J. B. P., et al. Produção Orgânica no Assentamento Itamarati em Ponta Porã, estado do Mato Grosso do Sul, Brasil. Cadernos de Agroecologia, v. 9, n. 4, nov. 2014.

GRAZIANO da SILVA, J. O novo rural brasileiro. 2. ed. Campinas, UNICAMP, IE, 1999.

GUZZATTI, T. C., et al. Novas relações entre os agricultores familiares e consumidores: perspectivas recentes no Brasil e na França. Organizações Rurais e Agroindustriais, v. 16, n. 3, 2014, p. 363-375.

HEBERLÊ, A. L. O., et al. Agricultura familiar e pesquisa agropecuária: contribuições para uma agenda de futuro ${ }^{100}$. 2017. IN: DELGADO, G. C.; BERGAMASCO, S. M. P. P. (orgs.). Agricultura familiar brasileira: desafios e perspectivas de futuro. Brasília: Ministério do Desenvolvimento Agrário, 2017. 
IBGE - INSTITUTO BRASILEIRO DE GEOGRAFIA E ESTATÍSTISCA. Censo Agropecuário 2017. Disponível em: https://sidra.ibge.gov.br/pesquisa/censoagropecuario/censo-agropecuario-2017\#cna. Acesso em: 06 jun. 2020.

LACKI, P. Buscando soluções para a crise no agro: no guichê do banco ou no banco da escola?. Santiago, Chile: FAO, 1998.

LIMA, D. M. A.; WILKINSON, J. (orgs.) Inovações nas tradições da agricultura familiar. Brasília: CNPq/Paralelo 15, 2002.

LOEBLEIN, G. Universidade cria plataforma para compra e venda de produtos da agricultura familiar. 2020. Disponível em: https://gauchazh.clicrbs.com.br/fiquebem/noticia/2020/05/universidade-cria-plataforma-para-compra-e-venda-deprodutos-da-agricultura-familiar-ck9x3v1tlooio015nd21kqts6.html. Acesso em: 05 jun. 2020.

LUCIANO, W. R. Agricultura familiar no contexto da feira do produtor rural: "feira corujão" no município de Rio Claro -SP. 2017. 57 f. Trabalho de Conclusão de Curso (Bacharelado em Geografia) - Instituto de Geociências e Ciências Exatas, Universidade Estadual Paulista, Rio Claro, São Paulo, 2017.

MATTAR, F. Pesquisa de marketing: metodologia e planejamento. 3. ed. São Paulo: Atlas. 1996.

MEDEIROS, J. K., et al. O desenvolvimento científico tecnológico e a agricultura familiar. IN: LIMA, D. M. A.; WILKINSON, J. (Orgs.) Inovações nas tradições da agricultura familiar. Brasília? CNPq/Paralelo 15, 2002, p. 23-38.

NEVES, D. P. A agricultura familiar e o claudicante quadro institucional. IN: LOPES, E. S. A.; MOTA, D. M.; SILVA, T. E. M. (orgs.) Ensaios: desenvolvimento rural e transformações na agricultura. Aracaju: Embrapa Tabuleiros Costeiros, Universidade Federal do Sergipe, 2002, p. 133-159.

PIMENTEL, R. F. Internet, mercados e hierarquias. Relatórios de Pesquisa em Engenharia da Produção da Universidade Federal Fluminense, Rio de Janeiro, v. 1, 2002.

ROMEIRO, A. R. Meio ambiente e dinâmica de inovações na agricultura. São Paulo: Annablume, FAPESP, 1998.

SCHNEIDER, S., et al. Introdução. 2016. IN: MARQUES, F. C.; CONTERATO, M. A.; SCHNEIDER, S. Construção de mercados e agricultura familiar: desafios para o desenvolvimento rural. Porto Alegre: Editora UFRGS, 2016.

SERENINI, M. J.; MALYSZ, S. T. A importância da agricultura familiar na produção de alimentos, 2014. IN: PARANÁ. Secretaria de Estado da Educação. Superintendência 
de Educação. Os desafios da escola pública paranaense na perspectiva do professor PDE, Curitiba: SEED/PR, 2016, v. 1. (Cadernos PDE).

SILVA, F. G.; MARTINELLI, L. A. S. Economia e mercado. Curitiba, PR: IFPR, 2012.

SOUZA FILHO, H. M., et al. Agricultura familiar e tecnologia no Brasil: características, desafios e obstáculos. IN: XLII Congresso da Sober, 2004, Cuiába. Anais do XLII Congresso da Sober, 2004, v. 1, p. 1-20.

SOUZA FILHO, H. M., et al. Condicionantes da adoção de inovações tecnológicas na agricultura. Cadernos de Ciência e Tecnologia, Brasília, v. 28, n. 1, jan.-abr. 2011, p. 223-255.

WANDERLEY, M. N. B. Agricultura familiar e campesinato: rupturas e continuidade. Estudos, Sociedade e Agricultura (UFRJ), v. 21, 2004, p. 42-61.

. O mundo rural como um espaço de vida: reflexões sobre a propriedade da terra, agricultura familiar e ruralidade. Porto Alegre: UFGRS, 2009.

ZARDO, R. A. Canais de comercialização de produtos da agricultura familiar na região oeste do Paraná. 2012. 90 f. Trabalho de Conclusão de Curso (Especialização) Departamento de Economia Rural e Extensão, Universidade Federal do Paraná, Curitiba, 2012.

Aldi Feiden. Graduação em Agronomia; Mestre e Doutor em Ecologia de Ambientes Aquáticos Continentais. Universidade Estadual do Oeste do Paraná Unioeste. Docente/Pesquisador. Universidade Estadual do Oeste do Paraná, Centro de Engenharia e Ciências Exatas, Campus de Toledo, Rua da Faculdade, 645, Jardim La Salle, cep. 85903-000, Toledo, PR - Brasil, caixa postal: 520. aldifeiden@gmail.com

Manoel João Ramos. Engenheiro de Produção Agroindustrial; Mestre em Desenvolvimento Regional e Agronegócio e Doutor em Recursos Pesqueiros e Engenharia de Pesca. Docente/Pesquisador na Faculdade da Indústria - Sistema FIEP/SENAI - Departamento Regional do Paraná, Serviço Nacional de Aprendizagem Industrial - Toledo, Rua Júlio de Castilhos, 3465, Vila Industrial, cep. 85904-175, Toledo, PR, Brasil.eng.major@hotmail.com

Jéssica Schwanke. Bacharela em Administração e Mestra em Desenvolvimento Rural Sustentável. Universidade Estadual do Oeste do Paraná - Unioeste. Estudante. Rua Recife, 1036, Alvorada, Marechal Cândido Rondon, PR, Brasil. jschwanke@hotmail.com 
Como citar: FEIDEN, Aldi; RAMOS, Manoel João; SCHWANKE, Jéssica. O comércio eletrônico como ferramenta de comercialização para a agricultura familiar. Redes (St. Cruz Sul, Online), Santa Cruz do Sul, v. 25, p. 2151-2170, 2020. ISSN 1982-6745. doi:https://doi.org/10.17058/redes.v25io.15092.

\section{CONTRIBUIÇÃO DE CADA AUTOR}

a. Fundamentação teórico-conceitual e problematização: Aldi Feiden, Manoel João Ramos e Jéssica Schwanke

b. Pesquisa de dados e análise estatística: Jéssica Schwanke

c. Elaboração de figuras e tabelas: Jéssica Schwanke

d. Fotos: Jéssica Schwanke

e. Elaboração e redação do texto: Jéssica Schwanke

f. Seleção das referências bibliográficas: Aldi Feiden, Manoel João Ramos e Jéssica

Schwanke

Fontes de financiamento: Não houve. 